\title{
ANALISA PERENCANAAN KEBUTUHAN BAHAN DENGAN KRITERIA MINIMASI BIAYA PERSEDIAAN BAHAN BAKU PADA PT. FAJAR UTAMA FURNISHING BEKASI
}

\author{
Hidayat, Heri Wibowo dan Hamdani Nurbahri \\ Program Studi Teknik Industri Universitas Malahayati Bandar Lampung \\ hidayat_49@rocketmail.com, heriwibowo_ti@yahoo.co.id
}

\begin{abstract}
Abstrak
PT. Fajar Utama Furnishing Bekasi adalah perusahaan yang memproduksi berbagai macam produk manufaktur seperti kursi, lemari, meja, sofa, dan lain sebagainya. Dalam menjalankan proses produksinya perincian bahan baku belum menggunakan suatu metode tertentu sehingga sering terjadi kelebihan dan kekurangan bahan, serta perencanaan produksi tidak berjalan lancar, sehingga menimbulkan biaya yang besar. Permasalahan yang dihadapi adalah agar produksi dapat optimal dan berjalan sesuai dengan yang diharapkan.Tujuan yang diharapkan dalam penelitian ini membuat perencanaan kebutuhan bahan sehingga produksi dapat berjalan dengan lancar dan mengefektifkan penggunaan sumber daya. Pembahasan dan analisa dilakukan dengan menggunakan rumus peramalan Exponential Smoothing untuk menentukan tingkat permintaan kursi sofa lois bundar (CH-547) pada periode Mei 2011- April 2012. Hasil peramalan ini digunakan untuk menentukan kebutuhan kotor dari produksi kursi sofa. Kemudian dilakukan perhitungan menggunakan metode MRP dengan sistem Lot For Lot, sehingga diperoleh perencanaan bahan baku.Berdasarkan perhitungan selama satu tahun jumlah total produksi sebesar 14958 unit, dimana biaya yang dikeluarkan menggunakan perhitungan MRP adalah $R p$ 6.545.072.150,- sedangkan biaya yang dikeluarkan menggunakan perhitungan perusahaan sebesar Rp 6.593.189.258,-, ini berarti terjadi penurunan biaya sebesar Rp48.117.108,-. Dengan adanya perencanaan kebutuhan bahan (Material Requirement Planning) maka persoalan biaya pengadaan bahan dan proses produksi akan dapat diatasi dan dapat berjalan sesuai dengan yang diharapkan.
\end{abstract}

Kata kunci : Biaya Persediaan, Perencanaan Kebutuhan Bahan

\section{PENDAhuluan}

Proses produksi merupakan salah satu kegiatan utama dari perusahaan, agar dapat menghasilkan produk bermutu sesuai dengan kebutuhan konsumen dan tepat waktu. Ketepatan proses produksi perlu didukung dengan ketepatan waktu dan jumlah pengadaan bahan baku sehingga produksi berjalan lancar dan pemenuhan kebutuhan pemesanan pelanggan dapat dipenuhi dengan tepat. Perusahaan harus bisa mengelola persediaan dengan baik agar dapat memiliki persediaan yang seoptimal mungkin demi kelancaran operasi perusahaan dalam jumlah, waktu, mutu yang tepat serta dengan biaya yang serendah rendahnya. Berdasarkan observasi awal ternyata persediaan bahan baku pada PT. Fajar Utama belum direncanakan dengan baik sehingga persediaan bahan baku yang diperusahaan kurang efektif dan proses produksi tidak dapat berjalan dengan lancar. Hal ini disebabkan karena kurangnya persediaan bahan baku yang ada digudang.

\section{TINJAUAN PUSTAKA}

Material Requrement Planning (MRP) merupakan suatu sistem perencanaan pengolahan material di dalam proses produksi atau manufaktur. Sistem ini juga merupakan media untuk menghitung jumlah material, waktu distribusi, jumlah stok pada sistem inventori dan prediksi kebutuhan material ataupun produk yang akan datang (menurut Hakim Nasution dalam Sunarti, 2009). Menurut Hendra Kusuma (2001), untuk dapat menerapkan material requirement planning pada dasarnya terdapat empat prasyarat yang harus dipenuhi yaitu:

a) Jadwal Induk Produksi

Jadwal induk Produksi (JIP) merupakan rencana rinci tentang jumlah barang yang akan diproduksi pada beberapa satuan waktu dalam horizon perencanaan. JIP merupakan optimasi 
ongkos dengan memperhatikan kapasitas yang tersedia dan ramalan permintaan untuk mencapai rencana produksi yang akan meminimasi total ongkos dan persediaan.

\section{b) Struktur Produk dan Bill Of Material}

Struktur produk berisi informasi mengenai hubungan antar komponen dalam perakitan. Informasi ini penting dalam penentuan kebutuhan kotor dan kebutuhan bersih suatu komponen.

c) Kejelasan dan Akurasi Catatan Persediaan

Sistem kerja MRP didasarkan atas persediaan yang dimiliki sehingga keputusan untuk membuat atau memesan barang pada suatu saat dapat dilakukan dengan sebaik-baiknya untuk itu tingkat persediaan komponen dan material harus selalu diamati.

d) Waktu Ancang

Waktu ancang ini diperlukan mengingat MRP memiliki dimensi masa waktu yang akan sangat berpengaruh terhadap pola persediaan komponen. Waktu ancang adalah waktu yang diperlukan mulai dari saat pesanan item dilakukan sampai dengan saat item tersebut diterima dan siap untuk digunakan. Waktu ancang inilah yang mempengaruhi kapan rencana pemesanan akan dilakukan.

Adapun elemen yang mempengaruhi waktu ancang adalah:

1. Waktu administrasi pesanan

2. Waktu set up pembuatan produk

3. Waktu pengiriman/gerak

4. Waktu proses pembuatan produk

5. Waktu antrian

Komponen-komponen dasar dari perencanan pengendalian bahan seperti diatas secara diagram dapat dilihat sebagai berikut:

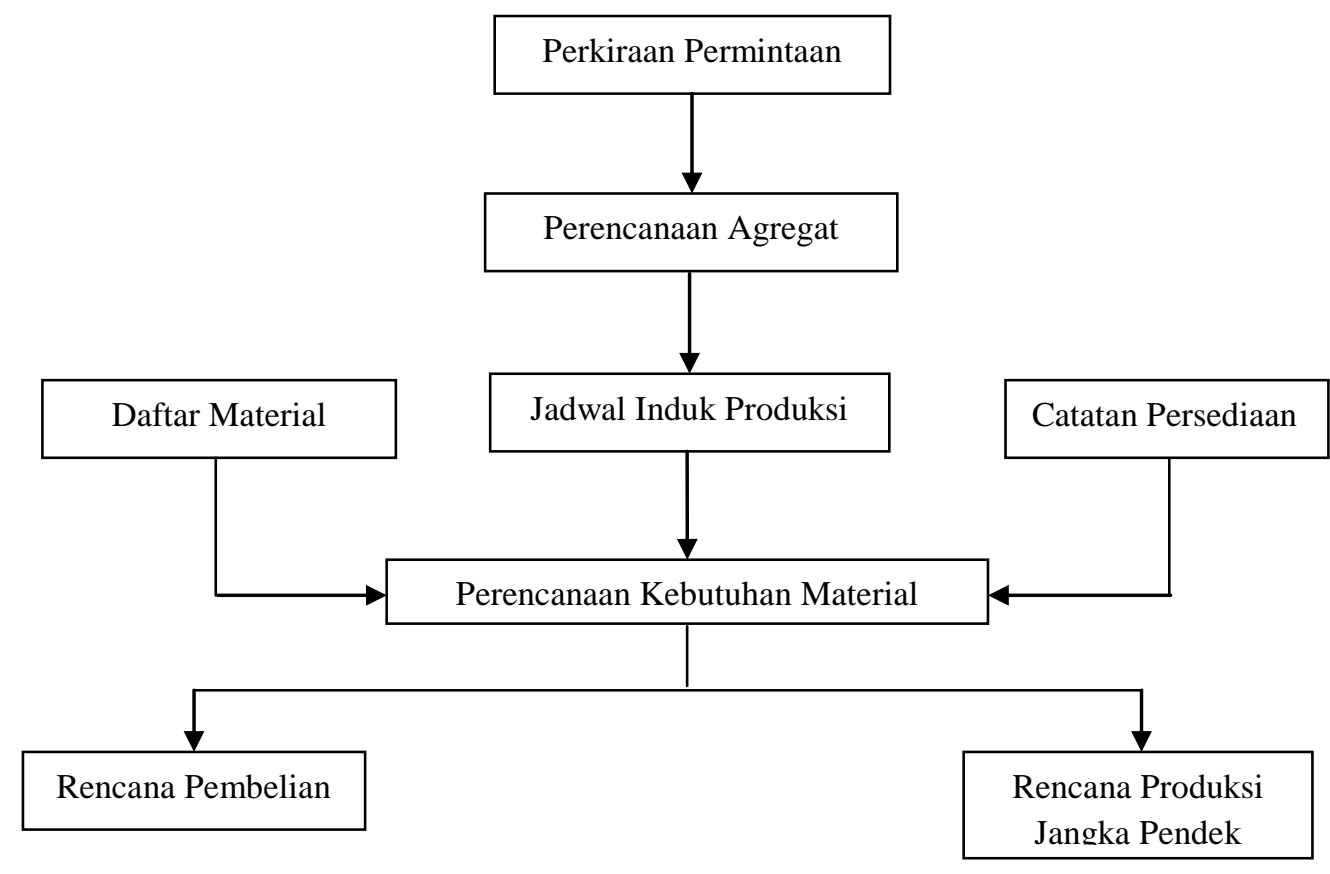

Gambar 1. Diagram Perencanaan Kebutuhan Bahan 
Adapun langkah-langkah dalam proses MRP adalah(Hendra Kusuma, 2001) :

a) Proses Netting

Netting adalah proses perhitungan untuk menetapkan jumlah kebutuhan bersih yang besarnya merupakan selisih antara kebutuhan kotor dengan keadaan persediaan (yang ada dalam persediaan dan yang sedang dipesan), masukan yang diperlukan dalam proses perhitungan kebutuhan bersih adalah:

1. Kebutuhan kotor, jumlah produk akhir yang akan dikonsumsi untuk tiap periode selama periode perencanaan

2. Rencana penerimaan dari subkontraktor selama periode perencanaan

3. Tingkat perencanaan yang dimiliki pada awal periode perencanaan

b) Proses Lotting

Proses lotting adalah proses untuk menentukan besarnya pesanan yang optimal untuk masing-masing item produk berdasarkan hasil perhitungan kebutuhan bersih. Proses lotting erat hubungannya dengan penentuan jumlah komponen/item yang harus dipesan/disediakan. Proses Lotting sendiri sangat penting dalam rencana kebutuhan bahan. Penggunaan dan pemiliha yang tepat sangat mempengaruhi keefektifan rencana kebutuhan bahan. Teknik lot sizing yang paling sederhana adalah dengan menggunakan konsep jumlah atau periode pemesanan yang tetap (lot for lot).

c) Proses Offsetting

Proses ini dilanjutkan untuk menentukan saat yang tepat guna melakukan rencana pemesanan dalam upaya memenuhi tingkat kebutuhan bersih. Rencana pemesanan dilakukan pada saat material dibutuhkan dikurangi dengan waktu ancang.

Pengertian waktu ancang disini adalah besarnya waktu yang diperlukan mulai dari saat pesan, tiba di gudang, diproduksi sampai barang tersebut selesai diterima dan siap dipakai.

d) Proses Explosion

Proses Explosion adalah proses perhitungan kotor item yang berada ditingkat lebih bawah didasarkan atas rencanapemesanan yang telah disusun pada proses ofsetting. Pada proses ini data struktur produk dan Bill Of Material memegang peran penting karena menentukan arah explosion item komponen.

Ukuran jumlah barang yang dipesan (lot size) akan berhubungan dengan biaya pemesanan (set up) dan biaya penyimpanan barang semakin rendah ukuran lot, berarti semakin sering melakukan pemesanan barang, akan menurunkan biaya penyimpanan, tetapi menambah biaya pemesanan barang akan menurunkan biaya penyimpanan, tetapi menambah biaya pamesanan. Sebaliknya semakin tinggi ukuran lot akan mengurangi frekuensi pemesanan, berarti mengurangi biaya pemesanan tetapi meningkatkan biaya penyimpanan. Untuk itu perlu dicari ukuran lot yang tepat agar dapat meminimalkan total biaya persediaan.

Adapun teknik teknik lot sebagai berikut (menurut Freddy dalam Setiawan2014):

1. Lot for lot (LFL)

Metode Lot for lot dikenal sebagai metode persediaan minimal berdasarkan ide penyediaan persediaan (memproduksi) sesuai dengan yang diperlukan saja, jumlah persediaan diusahakan seminimal mungkin.Jika pesanan dapat dilakukan dalam jumlah berapa saja,maka pesanan sesuai dengan jumlah yang sesungguhnya diperlukan (lot for lot) menghasilkan tidak adanya persediaan. Biaya yang timbul berupa biaya pemesanan saja. Metode ini beresiko tinggi, yaitu apabila terjadi keterlambatan dalam pengiriman barang, maka akan mengakibatkan terhentinya produksi.

2. Economic Order Quantity (EOQ)

Metode ini digunakan untuk permintaan yang tidak seragam dalam beberapa periode. Ratarata permintaan dipergunakan untuk mendapatkan rata-rata jumlah bahan setiap kali pemesanan, rata-rata permintaan beberapa periode dijumlahkan selanjutnya dibagi dengan jumlah periode yang ada danhasilnya dibulatkan ke dalam angka integer. Angka terakhir yang menunjukkan jumlah ekonomis dalam setiap kali pemesanan. 


\section{METODOLOGI PENELITIAN}

Tahapan penelitian diawali peramalan permintaan dengan metode Rata-rata bergerak (Moving Average) dan Exponential Smoothing dan standar deviasi menggunakan metode Mean Absolute Persentage Error (MAPE), penjadwalan induk produksi (Master Production Schadule), struktur kapasitas (Bill Of Material) dan perencanaan kebutuhan bahan (Material Requirement Planning) menggunakan sistem Lot For Lot.

\section{HASIL DAN PEMBAHASAN}

Tabel 1. Data Permintaan pada Periode Mei 2010 -April 2011

\begin{tabular}{l|c}
\hline \multicolumn{1}{c|}{ Bulan } & Jumlah Produksi \\
\hline Mei & 1326 \\
Juni & 1150 \\
Juli & 776 \\
Agustus & 1247 \\
September & 957 \\
Oktober & 1122 \\
November & 1056 \\
Desember & 856 \\
Januari & 1658 \\
Februari & 1343 \\
Maret & 2076 \\
April & 1830 \\
\multicolumn{1}{c}{ Jumlah } & 15397 \\
\hline
\end{tabular}

Sumber : PT. Fajar Utama Furnishing

Tabel 2. Data Ukuran Komponen Pembentuk Kursi Sofa

\begin{tabular}{c|l|c|c|c|c}
\hline No & \multicolumn{1}{|c|}{ Komponen } & Ukuran & Jumlah & Jumlah & Total \\
\hline 1 & Rangka depan & $120 \times 12 \times 4$ & 5760 & 1 & $5760 \mathrm{~cm}^{3}$ \\
2 & Bingkai depan & $120 \times 10 \times 4$ & 4800 & 1 & $4800 \mathrm{~cm}^{3}$ \\
3 & Kaki depan & $30 \times 8 \times 6$ & 1440 & 2 & $2880 \mathrm{~cm}^{3}$ \\
4 & Bingkai samping & $60 \times 10 \times 4$ & 2400 & 2 & $4800 \mathrm{~cm}^{3}$ \\
5 & Rangka belakang & $120 \times 12 \times 4$ & 5760 & 1 & $5760 \mathrm{~cm}^{3}$ \\
6 & Bingkai belakang & $120 \times 10 \times 4$ & 4800 & 1 & $4800 \mathrm{~cm}^{3}$ \\
7 & Kaki belakang & $30 \times 8 \times 6$ & 1440 & 2 & $2880 \mathrm{~cm}^{3}$ \\
8 & Rangka dudukan & $52 \times 112 \times 3$ & 17472 & 1 & $17472 \mathrm{~cm}^{3}$ \\
9 & Busa dudukan & $106 \times 60 \times 10$ & 63600 & 1 & $63600 \mathrm{~cm}^{3}$ \\
10 & Kulit busa dudukan & $110 \times 60$ & 6600 & 1 & $6600 \mathrm{~cm}^{2}$ \\
11 & Rangka sandaran & $130 \times 45 \times 4$ & 23400 & 1 & $23400 \mathrm{~cm}^{3}$ \\
12 & Sandaran tangan & $30 \times 10 \times 4$ & 1200 & 2 & $2400 \mathrm{~cm}^{3}$ \\
13 & Busa sandaran & $130 \times 45 \times 10$ & 58500 & 1 & $58500 \mathrm{~cm}^{3}$ \\
14 & Busa sandaran tangan & $30 \times 10 \times 10$ & 3000 & 2 & $6000 \mathrm{~cm}^{3}$ \\
15 & Kulit busa sandaran & $130 \times 45$ & 5850 & 1 & $5850 \mathrm{~cm}^{2}$ \\
16 & Kulit busa sandaran tangan & $30 \times 10$ & 300 & 2 & $600 \mathrm{~cm}^{2}$ \\
\hline
\end{tabular}

Sumber : PT. Fajar Utama Furnishing 


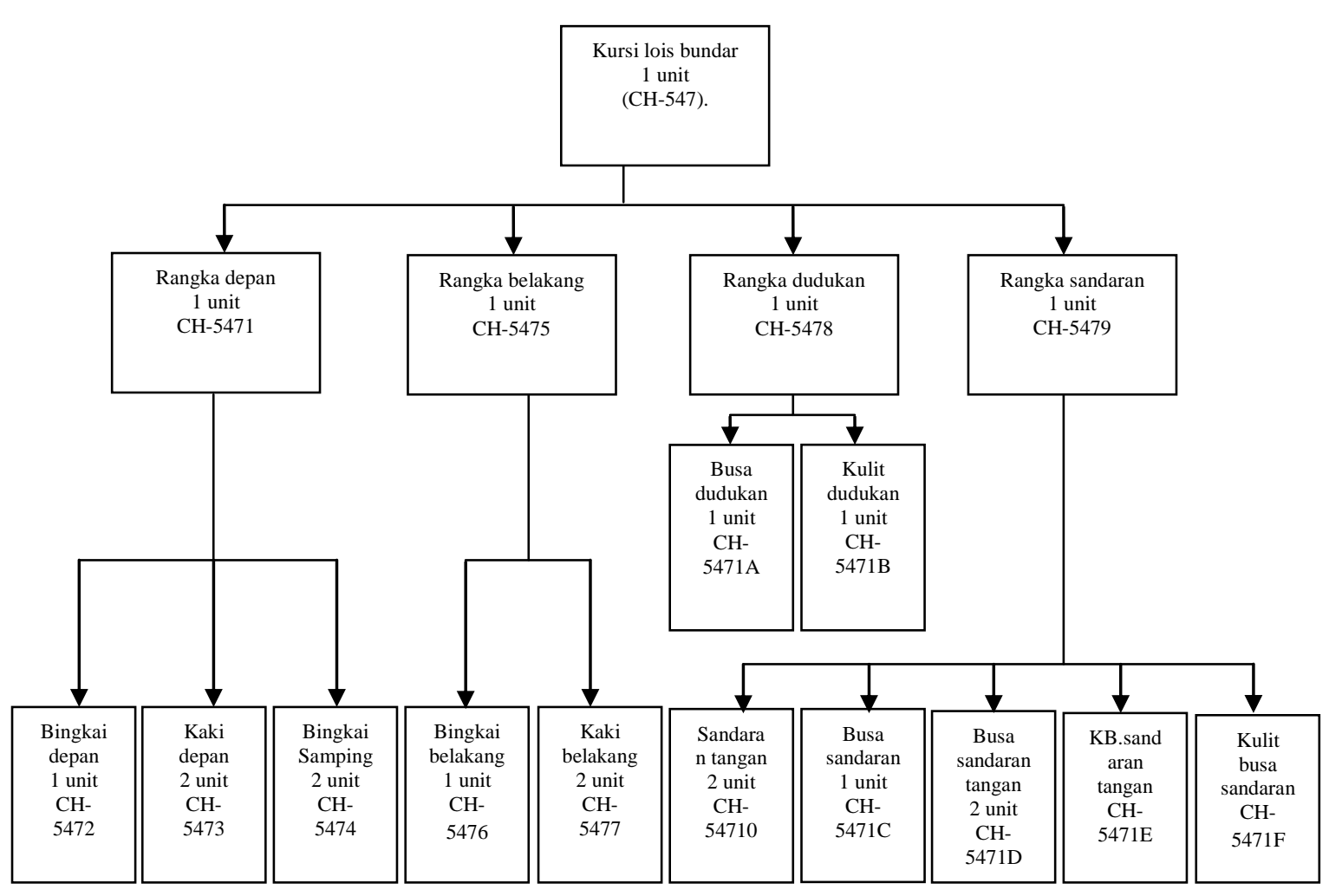

Gambar 2.Struktur Produk Kursi Sofa Lois Bundar (CH-547)

Tabel 3. Hasil Peramalan Kursi Sofa Dengan Metode Moving Average

\begin{tabular}{l|c|c|c|c|c}
\hline \multicolumn{1}{c}{ Bulan } & Dt & Dt' & $\left(\mathrm{dt}-\mathrm{dt} \mathrm{t}^{\prime}\right)$ & $\frac{d t-d t^{\prime}}{d t}$ & $\frac{\mathrm{dt}-\mathrm{dt}}{d t} \mid x 100$ \\
\hline Mei & 1326 & 1,326 & 0 & 0 & 0 \\
Juni & 1150 & 1,238 & -88 & 0.08 & 8 \\
Juli & 776 & 1,084 & -308 & 0.4 & 40 \\
Agustus & 1247 & 1,058 & 189.33 & 0.15 & 15 \\
September & 957 & 993 & -36.33 & 0.04 & 4 \\
Oktober & 1122 & 1,109 & 13.33 & 0.01 & 1 \\
November & 1056 & 1,045 & 11 & 0.01 & 1 \\
Desember & 856 & 1,011 & -155.33 & 0.18 & 28 \\
Januari & 1658 & 1,190 & 468 & 0.28 & 4 \\
Februari & 1343 & 1,285 & 57.33 & 0.04 & 18 \\
Maret & 2076 & 1,692 & 383.67 & 0.18 & 4 \\
April & 1830 & 1,749 & 80.33 & 0.04 & 141 \\
\hline
\end{tabular}

Perhitungan standar eror adalah sebagai berikut :

$$
\begin{aligned}
\text { MAPE } & =\left(\frac{100}{n}\right) \sum\left|\frac{d t-d t^{\prime}}{d t}\right| \\
\text { MAPE } & =\frac{141}{12} \\
& =11,75 \%
\end{aligned}
$$


Tabel 4. Hasil Peramalan Kursi Sofa Dengan Metode Exponential Smoothing

\begin{tabular}{l|c|c|c|c|c}
\hline \multicolumn{1}{c|}{ Bulan } & $\mathrm{dt}$ & $\mathrm{Dt}$ & $\left(\mathrm{dt}-\mathrm{dt} \mathrm{t}^{\prime}\right)$ & $\frac{d t-d t^{\prime}}{d t}$ & $\frac{\mathrm{dt}^{\prime}-\mathrm{dt}^{\prime}}{d t} \mid x 100$ \\
\hline Mei & 1326 & 1326 & 0 & 0 & 0 \\
Juni & 1150 & 1238 & -88 & -0.08 & 8 \\
Juli & 776 & 1007 & -231 & -0.30 & 30 \\
Agustus & 1247 & 1127 & 120 & 0.10 & 10 \\
September & 957 & 1042 & -85 & -0.09 & 9 \\
Oktober & 1122 & 1082 & 40 & 0.04 & 1 \\
November & 1056 & 1069 & -13 & -0.01 & 12 \\
Desember & 856 & 963 & -106 & -0.12 & 21 \\
Januari & 1658 & 1310 & 347 & 0.21 & 1 \\
Februari & 1343 & 1327 & 16 & 0.01 & 18 \\
Maret & 2076 & 1701 & 374 & 0.18 & 4 \\
April & 1830 & 1766 & 64 & 0.04 & 118 \\
& 15397 & 14958 & & & \\
\hline
\end{tabular}

Perhitungan standar eror adalah sebagai berikut :

$$
\begin{aligned}
\text { MAPE } & =\left(\frac{100}{n}\right) \sum\left|\frac{d t-d t^{\prime}}{d t}\right| \\
\text { MAPE } & =\frac{118}{12} \\
& =9,8 \%
\end{aligned}
$$

Dari perhitungan kedua metode peramalan diperoleh nilai kesalahan peramalan untuk kursi sofa ini menggunakan exponential smoothing sebesar 9,8 persen lebih kecil dibandingkan menggunakan moving average sebasar 11,57 persen. Ini berarti bahwa dari hasil perhitungan peramalan menggunakan exponential smoothing dan analisis kesalahan peramalan menghasilkan nilai hampir mendekati data pada periode sebelumnya.

Dalam penyusunan jadwal induk produksi, periodenya adalah mingguan.Jadi berdasarkan hasil ramalan pada tabel 4 di atas, periode bulan dikonversikan ke periode minggu seperti

\begin{tabular}{|c|c|c|c|c|c|c|c|c|c|c|c|c|c|}
\hline \multirow{2}{*}{ Komponen } & \multirow{2}{*}{ Kode } & \multicolumn{12}{|c|}{ Jadwal Induk Produksi per Minggu Setiap Bulan } \\
\hline & & Mei & Juni & Juli & Agust & Sept & Okt & Nov & Des & Jan & Feb & Mart & April \\
\hline R. depan & $(\mathrm{CH}-5471)$ & 332 & 310 & 252 & 282 & 261 & 271 & 268 & 241 & 328 & 332 & 426 & 442 \\
\hline B.depan & (CH-5472) & 332 & 310 & 252 & 282 & 261 & 271 & 268 & 241 & 328 & 332 & 426 & 442 \\
\hline K. depan & (CH-5473) & 664 & 620 & 504 & 564 & 522 & 542 & 536 & 482 & 656 & 664 & 852 & 884 \\
\hline B. samping & (CH-5474) & 664 & 620 & 504 & 564 & 522 & 542 & 536 & 482 & 656 & 664 & 852 & 884 \\
\hline R. belakang & (CH-5475) & 332 & 310 & 252 & 282 & 261 & 271 & 268 & 241 & 328 & 332 & 426 & 442 \\
\hline B. belakang & (CH-5476) & 332 & 310 & 252 & 282 & 261 & 271 & 268 & 241 & 328 & 332 & 426 & 442 \\
\hline K. belakang & (CH-5477) & 664 & 620 & 504 & 564 & 522 & 542 & 536 & 482 & 656 & 664 & 852 & 884 \\
\hline R. dudukan & (CH-5478) & 332 & 310 & 252 & 282 & 261 & 271 & 268 & 241 & 328 & 332 & 426 & 442 \\
\hline B.dudukan & (CH-5471A) & 332 & 310 & 252 & 282 & 261 & 271 & 268 & 241 & 328 & 332 & 426 & 442 \\
\hline K. b. dudukan & $(\mathrm{CH}-5471 \mathrm{~B})$ & 332 & 310 & 252 & 282 & 261 & 271 & 268 & 241 & 328 & 332 & 426 & 442 \\
\hline R.sandaran & (CH-5471) & 332 & 310 & 252 & 282 & 261 & 271 & 268 & 241 & 328 & 332 & 426 & 442 \\
\hline S. tangan & (CH-5471) & 664 & 620 & 504 & 564 & 522 & 542 & 536 & 482 & 656 & 664 & 852 & 884 \\
\hline B. sandaran & (CH-5 & 332 & 310 & 252 & 282 & 261 & 271 & 268 & 241 & 328 & 332 & 426 & 442 \\
\hline daran & $(\mathrm{CH}-$ & 332 & 310 & 252 & 282 & 261 & 271 & 268 & 241 & 328 & 332 & 426 & 442 \\
\hline B.s. tangan & (CH-5 & 664 & 620 & 504 & 564 & 522 & 542 & 536 & 482 & 656 & 664 & 852 & 884 \\
\hline K.b. s. tangan & (CH-5471F) & 664 & 620 & 504 & 564 & 522 & 542 & 536 & 482 & 656 & 664 & 852 & 884 \\
\hline
\end{tabular}
yang terurai pada tabel 5 berikut ini.

Tabel 5. Jadwal Induk Produksi Perkomponen Untuk Satu Tahun Yang Akan Datang

Tabel jadwal induk produksi di atas dapat digunakan sebagai masukan (input) untuk menyusun perencanaan kebutuhan bahandan biaya lot for lot secara lengkap pada tabel 6 sampai tabel 9 berikut ini. 
Tabel 6. MRP Produk Kursi Sofa Lois Bundar

\begin{tabular}{|c|c|c|c|c|c|c|c|c|c|c|c|c|c|}
\hline \multirow{2}{*}{\multicolumn{6}{|c|}{$\begin{array}{l}\text { Nama Komponen : Kursi Sofa } \\
\text { Kode }:(\mathrm{CH}-547)\end{array}$}} & \multirow{2}{*}{\multicolumn{8}{|c|}{$\begin{array}{l}\text { Order Quantity : Lot For Lot } \\
\text { Time: } 1 \text { Minggu }\end{array}$}} \\
\hline & & & & & & & & & & & & & \\
\hline Periode & & \multicolumn{4}{|c|}{ Mei } & \multicolumn{4}{|c|}{ Juni } & \multicolumn{4}{|c|}{ Juli } \\
\hline Minggu & & 1 & 2 & 3 & 4 & 5 & 6 & 7 & 8 & 9 & 10 & 11 & 12 \\
\hline Keb. kotor & & 332 & 332 & 332 & 332 & 310 & 310 & 310 & 310 & 252 & 252 & 252 & 252 \\
\hline \multicolumn{14}{|l|}{ Pnrm. Terjadwal } \\
\hline \multicolumn{14}{|l|}{ Persed. Ditangan } \\
\hline Keb. bersih & & 332 & 332 & 332 & 332 & 310 & 310 & 310 & 310 & 252 & 252 & 252 & 252 \\
\hline Pesanan yang diterima & & 332 & 332 & 332 & 332 & 310 & 310 & 310 & 310 & 252 & 252 & 252 & 252 \\
\hline \multicolumn{14}{|l|}{ Persed. akhir } \\
\hline Pelepasan Pesanan & 332 & 332 & 332 & 332 & 310 & 310 & 310 & 310 & 252 & 252 & 252 & 252 & 282 \\
\hline Periode & & \multicolumn{4}{|c|}{ Agustus } & \multicolumn{4}{|c|}{ September } & \multicolumn{4}{|c|}{ Oktober } \\
\hline Minggu & & 13 & 14 & 15 & 16 & 17 & 18 & 19 & 20 & 21 & 22 & 23 & 24 \\
\hline Keb. kotor & & 282 & 282 & 282 & 282 & 261 & 261 & 261 & 261 & 271 & 271 & 271 & 271 \\
\hline \multicolumn{14}{|l|}{ Pnrm. Terjadwal } \\
\hline \multicolumn{14}{|l|}{ Persed. Ditangan } \\
\hline Keb. bersih & & 282 & 282 & 282 & 282 & 261 & 261 & 261 & 261 & 271 & 271 & 271 & 271 \\
\hline Pesanan yang diterima & & 282 & 282 & 282 & 282 & 261 & 261 & 261 & 261 & 271 & 271 & 271 & 271 \\
\hline \multicolumn{14}{|l|}{ Persed. akhir } \\
\hline Pelepasan Pesanan & 282 & 282 & 282 & 282 & 282 & 261 & 261 & 261 & 271 & 271 & 271 & 271 & 268 \\
\hline Periode & & \multicolumn{4}{|c|}{ November } & \multicolumn{4}{|c|}{ Desember } & \multicolumn{4}{|c|}{ Januari } \\
\hline Minggu & & 25 & 26 & 27 & 28 & 29 & 30 & 31 & 32 & 33 & 34 & 35 & 36 \\
\hline Keb. kotor & & 268 & 268 & 268 & 268 & 241 & 241 & 241 & 241 & 328 & 328 & 328 & 328 \\
\hline \multicolumn{14}{|l|}{ Pnrm. Terjadwal } \\
\hline \multicolumn{14}{|l|}{ Persed. Ditangan } \\
\hline Keb. bersih & & 268 & 268 & 268 & 268 & 241 & 241 & 241 & 241 & 328 & 328 & 328 & 328 \\
\hline Pesanan yang diterima & & 268 & 268 & 268 & 268 & 241 & 241 & 241 & 241 & 328 & 328 & 328 & 328 \\
\hline \multicolumn{14}{|l|}{ Persed. akhir } \\
\hline Pelepasan Pesanan & 268 & 268 & 268 & 268 & 241 & 241 & 241 & 241 & 328 & 328 & 328 & 328 & 332 \\
\hline Periode & & \multicolumn{4}{|c|}{ Februari } & \multicolumn{4}{|c|}{ Maret } & \multicolumn{4}{|c|}{ April } \\
\hline Minggu & & 37 & 38 & 39 & 40 & 41 & 42 & 43 & 44 & 45 & 46 & 47 & 48 \\
\hline Keb. kotor & & 332 & 332 & 332 & 332 & 426 & 426 & 426 & 426 & 442 & 442 & 442 & 442 \\
\hline Pnrm. Terjadwal & & & & & & & & & & & & & \\
\hline Persed. Ditangan & & & & & & & & & & & & & \\
\hline Keb. bersih & & 332 & 332 & 332 & 332 & 426 & 426 & 426 & 426 & 442 & 442 & 442 & 442 \\
\hline Pesanan yang diterima & & 332 & 332 & 332 & 332 & 426 & 426 & 426 & 426 & 442 & 442 & 442 & 442 \\
\hline Persed. akhir & & & & & & & & & & & & & \\
\hline Pelepasan Pesanan & 332 & 332 & 332 & 332 & 426 & 426 & 426 & 426 & 442 & 442 & 442 & 442 & \\
\hline
\end{tabular}

Tabel 7.Ringkasan Rencana Kebutuhan Bahan Baku (dalam Unit)

\begin{tabular}{|c|c|c|c|c|c|c|c|c|c|c|c|c|c|c|}
\hline \multirow{2}{*}{ Komponen } & \multirow{2}{*}{ Sat. } & \multicolumn{12}{|c|}{ Bulan } & \multirow{2}{*}{ Jumlah } \\
\hline & & Mei & Juni & Juli & Agu & Sept & Okt & Nov & Des & Jan & Feb & Mar & Apr & \\
\hline R. depan & Unit & 1306 & 1182 & 1038 & 1107 & 1054 & 1081 & 1045 & 1051 & 1316 & 1422 & 1720 & 1326 & 14648 \\
\hline B.depan & Unit & 1306 & 1182 & 1038 & 1107 & 1054 & 1081 & 1045 & 1051 & 1316 & 1422 & 1720 & 1326 & 14648 \\
\hline K. depan & Unit & 2612 & 2364 & 2076 & 2214 & 2108 & 2162 & 2090 & 2102 & 2632 & 2844 & 3440 & 2652 & 29296 \\
\hline B. samping & Unit & 2612 & 2364 & 2076 & 2214 & 2108 & 2162 & 2090 & 2102 & 2632 & 2844 & 3440 & 2652 & 29296 \\
\hline R. belakang & Unit & 1306 & 1182 & 1038 & 1107 & 1054 & 1081 & 1045 & 1051 & 1316 & 1422 & 1720 & 1326 & 14648 \\
\hline B. belakang & Unit & 1306 & 1182 & 1038 & 1107 & 1054 & 1081 & 1045 & 1051 & 1316 & 1422 & 1720 & 1326 & 14648 \\
\hline $\mathrm{K}$. belakang & Unit & 2612 & 2364 & 2076 & 2214 & 2108 & 2162 & 2090 & 2102 & 2632 & 2844 & 3440 & 2652 & 29296 \\
\hline R. dudukan & Unit & 1306 & 1182 & 1038 & 11 & 10 & 10 & 10 & 10 & 13 & 1422 & 1720 & 1326 & 14648 \\
\hline B.dudukan & Unit & 1250 & 1250 & 1000 & 1000 & 1250 & 1000 & 1000 & 1000 & 1500 & 1500 & 1500 & 1500 & 14750 \\
\hline $\begin{array}{l}\text { K. b. } \\
\text { dudukan }\end{array}$ & Unit & 1200 & 1200 & 1050 & 1200 & 1050 & 1050 & 1050 & 1050 & 1350 & 1350 & 1800 & 1200 & 14550 \\
\hline R.sandaran & Unit & 1306 & 1182 & 1038 & 1107 & 1054 & 1081 & 1045 & 1051 & 1316 & 1422 & 1720 & 1326 & 14648 \\
\hline S. tangan & Unit & 2612 & 2364 & 2076 & 2214 & 2108 & 2162 & 2090 & 2102 & 2632 & 2844 & 3440 & 2652 & 29296 \\
\hline B. sandaran & Unit & 1250 & 1250 & 1000 & 1000 & 1250 & 1000 & 1000 & 1000 & 1500 & 1500 & 1500 & 1500 & 14750 \\
\hline $\begin{array}{l}\text { K. b. } \\
\text { sandaran }\end{array}$ & Unit & 1200 & 1200 & 1050 & 1200 & 1050 & 1050 & 1050 & 1050 & 1350 & 1350 & 1800 & 1200 & 14550 \\
\hline B.s. tangan & Unit & 2750 & 2250 & 2000 & 2250 & 2250 & 2000 & 2250 & 2000 & 2750 & 2750 & 3500 & 2500 & 29250 \\
\hline $\begin{array}{l}\text { K.b. s. } \\
\text { tangan }\end{array}$ & Unit & 2550 & 2400 & 2100 & 2250 & 2100 & 2100 & 2100 & 2100 & 2700 & 2850 & 3450 & 2550 & 29250 \\
\hline Pellitur & ltr & 68 & 64 & 52 & 56 & 52 & 56 & 56 & 48 & 64 & 68 & 84 & 88 & 756 \\
\hline
\end{tabular}


Tabel 8.Ringkasan Rencana Kebutuhan Komponen OlahanKursi Sofa

\begin{tabular}{|c|c|c|c|c|c|c|c|c|c|c|c|c|c|}
\hline \multirow{2}{*}{ Komponen } & \multirow{2}{*}{ Sat. } & \multicolumn{12}{|c|}{ Bulan } \\
\hline & & Mei & Juni & Juli & Agu & Sept & Okt & Nov & Des & Jan & Feb & Mar & Apr \\
\hline R. depan & $\mathrm{m}^{3}$ & 7.52 & 6.81 & 5.98 & 6.38 & 6.07 & 6.23 & 6.02 & 6.05 & 7.58 & 8.19 & 9.91 & 7.64 \\
\hline B.depan & $\mathrm{m}^{3}$ & 6.27 & 5.67 & 4.98 & 5.31 & 5.06 & 5.19 & 5.02 & 5.04 & 6.32 & 6.83 & 8.26 & 6.36 \\
\hline K. depan & $\mathrm{m}^{3}$ & 7.52 & 6.81 & 5.98 & 6.38 & 6.07 & 6.23 & 6.02 & 6.05 & 7.58 & 8.19 & 9.91 & 7.64 \\
\hline B. samping & $\mathrm{m}^{3}$ & 12.54 & 11.35 & 9.96 & 10.63 & 10.12 & 10.38 & 10.03 & 10.09 & 12.63 & 13.65 & 16.51 & 12.73 \\
\hline R. belakang & $\mathrm{m}^{3}$ & 7.52 & 6.81 & 5.98 & 6.38 & 6.07 & 6.23 & 6.02 & 6.05 & 7.58 & 8.19 & 9.91 & 7.64 \\
\hline B. belakang & $\mathrm{m}^{3}$ & 6.27 & 5.67 & 4.98 & 5.31 & 5.06 & 5.19 & 5.02 & 5.04 & 6.32 & 6.83 & 8.26 & 6.36 \\
\hline K. belakang & $\mathrm{m}^{3}$ & 7.52 & 6.81 & 5.98 & 6.38 & 6.07 & 6.23 & 6.02 & 6.05 & 7.58 & 8.19 & 9.91 & 7.64 \\
\hline R. dudukan & $\mathrm{m}^{3}$ & 22.82 & 20.65 & 18.14 & 19.34 & 18.42 & 18.89 & 18.26 & 18.36 & 22.99 & 24.85 & 30.05 & 23.17 \\
\hline B.dudukan & $\mathrm{m}^{3}$ & 30.56 & 27.66 & 24.29 & 25.90 & 24.66 & 25.30 & 24.45 & 24.59 & 30.79 & 33.27 & 40.25 & 31.03 \\
\hline K. b. dudukan & $\mathrm{m}^{3}$ & 6.27 & 5.67 & 4.98 & 5.31 & 5.06 & 5.19 & 5.02 & 5.04 & 6.32 & 6.83 & 8.26 & 6.36 \\
\hline R.sandaran & $\mathrm{m}^{3}$ & 1250 & 1250 & 1000 & 1000 & 1250 & 1000 & 1000 & 1000 & 1500 & 1500 & 1500 & 1500 \\
\hline S. tangan & Unit & 1200 & 1200 & 1050 & 1200 & 1050 & 1050 & 1050 & 1050 & 1350 & 1350 & 1800 & 1200 \\
\hline B. sandaran & Unit & 1250 & 1250 & 1000 & 1000 & 1250 & 1000 & 1000 & 1000 & 1500 & 1500 & 1500 & 1500 \\
\hline $\begin{array}{l}\text { K. b. } \\
\text { sandaran }\end{array}$ & Unit & 1200 & 1200 & 1050 & 1200 & 1050 & 1050 & 1050 & 1050 & 1350 & 1350 & 1800 & 1200 \\
\hline B.s. tangan & Unit & 2750 & 2250 & 2000 & 2250 & 2250 & 2000 & 2250 & 2000 & 2750 & 2750 & 3500 & 2500 \\
\hline K.b. s. tangan & Unit & 2550 & 2400 & 2100 & 2250 & 2100 & 2100 & 2100 & 2100 & 2700 & 2850 & 3450 & 2550 \\
\hline Pellitur & ltr & 68 & 64 & 52 & 56 & 52 & 56 & 56 & 48 & 64 & 68 & 84 & 88 \\
\hline
\end{tabular}

Tabel 9. Perhitungan Biaya Lot For Lot (dalam Rupiah)

\begin{tabular}{|c|c|c|c|c|c|c|}
\hline \multirow{2}{*}{ Komponen } & \multicolumn{5}{|c|}{ Bulan } & \multirow{2}{*}{ Jumlah } \\
\hline & Mei & Juni & $\ldots \ldots$ & Mar & Apr & \\
\hline R. depan & $31,218,624$ & $28,254,528$ & $\ldots \ldots$ & $41,114,880$ & $31,696,704$ & \\
\hline B.depan & $26,015,520$ & $23,545,440$ & $\ldots \ldots$ & $34,262,400$ & $26,413,920$ & \\
\hline K. depan & $31,218,624$ & $28,254,528$ & $\ldots \ldots$ & $41,114,880$ & $31,696,704$ & \\
\hline B. samping & $52,031,040$ & $47,090,880$ & $\ldots \ldots$ & $68,524,800$ & $52,827,840$ & \\
\hline R. belakang & $31,218,624$ & $28,254,528$ & $\ldots \ldots$ & $41,114,880$ & $31,696,704$ & \\
\hline B. belakang & $26,015,520$ & $23,545,440$ & $\ldots \ldots$ & $34,262,400$ & $26,413,920$ & \\
\hline K. belakang & $31,218,624$ & $28,254,528$ & $\ldots \ldots$ & $41,114,880$ & $31,696,704$ & \\
\hline R. dudukan & $94,696,493$ & $85,705,402$ & $\ldots \ldots$ & $124,715,136$ & $96,146,669$ & \\
\hline B.dudukan & $126,825,660$ & $114,784,020$ & $\ldots \ldots$ & $167,029,200$ & $128,767,860$ & \\
\hline K. b. dudukan & $26,015,520$ & $23,545,440$ & $\ldots \ldots$ & $34,262,400$ & $26,413,920$ & \\
\hline R.sandaran & $18,750,000$ & $18,750,000$ & $\ldots \ldots$ & $22,500,000$ & $22,500,000$ & \\
\hline S. tangan & $18,750,000$ & $18,750,000$ & $\ldots \ldots$ & $22,500,000$ & $22,500,000$ & \\
\hline B. sandaran & $41,250,000$ & $33,750,000$ & $\ldots \ldots$ & $52,500,000$ & $37,500,000$ & \\
\hline K. b. sandaran & $6,000,000$ & $6,000,000$ & $\ldots \ldots$ & $9,000,000$ & $6,000,000$ & \\
\hline B.s. tangan & $6,000,000$ & $6,000,000$ & $\ldots$. & $9,000,000$ & $6,000,000$ & \\
\hline K.b. s. tangan & $12,750,000$ & $12,000,000$ & $\ldots \ldots$ & $17,250,000$ & $12,750,000$ & \\
\hline Pellitur & $2,516,000$ & $2,368,000$ & $\ldots \ldots$ & $3,108,000$ & $3,256,000$ & \\
\hline Jumlah & $582,490,249$ & $528,852,734$ & $\ldots \ldots$ & $763,373,856$ & $594,276,945$ & $6,545,072,150$ \\
\hline
\end{tabular}

Berdasarkan perhitungan dengan menggunakan metode MRP mulai tabel 6 sampai tabel 9, diperoleh biaya lot for lot yang dikeluarkan sebesar Rp 6.545.072.150,-. Tabel 7 dan tabel 8 adalah ringkasan kebutuhan bahan baku dari tabel 6 yang dikonversi menjadi kubikasi dengan tujuan untuk menghitung jumlah biaya pada tabel 9 , yang harus dikeluarkan dalam memenuhi kebutuhan bahan baku mulai dari pemasok bahan baku sampai diterima digudang bahan baku utama. 
Tabel 10. Perhitungan Biaya Perusahaan (dalam Rupiah)

\begin{tabular}{|c|c|c|c|c|c|c|}
\hline \multirow{2}{*}{ Komponen } & \multicolumn{5}{|c|}{ Bulan } & \multirow{2}{*}{ Jumlah } \\
\hline & Mei & Juni & ....... & Mar & Apr & \\
\hline R. depan & $31,696,704$ & $29,593,152$ & ....... & $40,660,704$ & $42,214,464$ & \\
\hline B.depan & $26,413,920$ & $24,660,960$ & ....... & $33,883,920$ & $35,178,720$ & \\
\hline K. depan & $31,696,704$ & $29,593,152$ & ....... & $40,660,704$ & $42,214,464$ & \\
\hline B. samping & $52,827,840$ & $49,321,920$ & ....... & $67,767,840$ & $70,357,440$ & \\
\hline R. belakang & $31,696,704$ & $29,593,152$ & $\ldots \ldots$ & $40,660,704$ & $42,214,464$ & \\
\hline B. belakang & $26,413,920$ & $24,660,960$ & $\ldots \ldots$ & $33,883,920$ & $35,178,720$ & \\
\hline K. belakang & $31,696,704$ & $29,593,152$ & ....... & $40,660,704$ & $42,214,464$ & \\
\hline R. dudukan & $96,146,669$ & $89,765,894$ & ....... & $123,337,469$ & $128,050,541$ & \\
\hline B.dudukan & $128,767,860$ & $120,222,180$ & $\ldots \ldots$ & $165,184,110$ & $171,496,260$ & \\
\hline K. b. dudukan & $13,206,960$ & $12,330,480$ & $\ldots \ldots$ & $16,941,960$ & $17,589,360$ & \\
\hline R.sandaran & $22,500,000$ & $18,750,000$ & $\ldots \ldots$ & $26,250,000$ & $26,250,000$ & \\
\hline S. tangan & $6,750,000$ & $6,750,000$ & $\ldots \ldots$ & $9,000,000$ & $9,000,000$ & \\
\hline B. sandaran & $22,500,000$ & $18,750,000$ & $\ldots \ldots$ & $26,250,000$ & $26,250,000$ & \\
\hline K. b. sandaran & $6,750,000$ & $6,750,000$ & $\ldots \ldots$ & $9,000,000$ & $9,000,000$ & \\
\hline B.s. tangan & $41,250,000$ & $37,500,000$ & ....... & $52,500,000$ & $52,500,000$ & \\
\hline K.b. s. tangan & $13,500,000$ & $12,750,000$ & ....... & $17,250,000$ & $18,000,000$ & \\
\hline Pellitur & $2,516,000$ & $2,368,000$ & $\ldots \ldots$ & $3,108,000$ & $3,256,000$ & \\
\hline Jumlah & $586,329,985$ & $542,953,002$ & ....... & $747,000,035$ & $770,964,897$ & $6,593,189,258$ \\
\hline
\end{tabular}

Dari hasil perhitungan dengan menggunakan metode LFL, maka didapat suatu perbandingan dimana dalam perencanaan kebutuhan bahan yang dilakukan perusahaan selama satu tahun mengeluarkan biaya sebesar $\mathrm{Rp}$ 6.593.189.258,-, ini berarti terjadi penghematan biaya sebesar Rp 48.117.108,- bila dibandingkan dengan tabel perhitungan biaya LFL.Pengeluaran biaya yang cukup besar oleh perusahaan disebabkan oleh pelaksanaan pembelian ataupun pemesanan bahan yang dilakukan berdasarkan rutinitas bulanan. Sehingga menyebabkan pembengkakan biaya pada beberapa bagian, seperti pada biaya pemesanan, terlalu sering melakukan pemesanan maka biaya yang harus dikeluarkan akan semakin besar. Tidak hanya itu pada faktor produksipun akan terhambat, seperti kekurangan bahan ataupun penumpukan bahan digudang dan akan menambah pengeluaran biaya bagi perusahaan.

\section{KESIMPULAN DAN SARAN}

\section{A. Kesimpulan}

Dari hasil pembahasan yang sudah dilakukan, maka dapat ditarik kesimpulan :

1. Perencanaan bahan baku dengan pendekatan Material Requirement Planning (MRP) dengan sistem Lot For Lot selama satu tahun dengan jumlah sebesar 14.958 unit

2. Berdasarkan perhitungan biaya pengendalian persediaan menggunakan metode Material Requirement Planning (MRP) dapat menekan atau memperkecil pembebanan biaya pengadaan bahan baku produksi sebesar Rp48.117.108,-, hal ini diakibatkan karena sistem Lot For Lot yang digunakan disini tidak terdapat persediaan pada gudang yang digunakan sebagai stok pengaman (Safety stock).

\section{B. Saran}

Adapun beberapa saranyang dapat diberikan antara lain :

1. Pihak perusahaan diharapkan lebih memperhatikan sistem perencanaan kebutuhan bahan baku dengan lebih teliti dan terencana untuk kelancaran proses produksi.

2. Dalam sistem pengadaan bahan baku, sebaiknya diperhitungkan jumlah yang paling optimal dalam melakukan pemesanan agar biaya yang dikeluarkan dapat ditekan seminimal mungkin, dan dalam penelitian ini kami ajukan metode Lot For Lot, walaupun sebenarnya masih banyak metode yang bisa digunakan dalam mengatasi permasalahan ini.

3. Untuk penelitian selanjutnya banyak metode yang dapat digunakan dalam perhitungan ini, seperti dalam metode peramalan untuk menentukan jadwal induk produksi atau menentukan besarnya lot dalam penyusunan MRP yang menggunakan 
beberapa sistem, seperti Lot For Lot, POQ (Periode Order Quantity), EOQ (Economic Order Quantity) atau yang lainnya.

\section{DAFTAR PUSTAKA}

[1] Hakim Nasution, Arman. 2001. Perencanaan dan Pengendalian Persediaan.Jakarta : Elexindo Media.

[2] Hakim Nasution, Arman. 2005. Manajemen Industri. Yogyakarta : Andi Offset.

[3] Handoko, T. Hani. 2008. Dasar- dasar Manajemen Produksi dan Operasi Edisi ke-4. Yogyakarta : BPFE Universitas Gadjah Mada.

[4] Kusuma, Hendra. 2001. Perencanaan dan Pengendalian Produksi Edisi Pertama. Yogyakarta : Andi Offset.

[5] Rangkuti, Freddy. 2000. Manajemen Persediaan. Jakarta :Raja Grafindo Persada.

[6] Setiawan, Aris. 2014. Perencanaan Kebutuhan Bahan Baku Produk Kursi Bambu Panjang Dengan Pendekatan Minimasi Biaya : Studi Kasus Pada CV. Meubel Makmur Sejahtera. Bandar Lampung : Program Studi Teknik Industri Universitas Malahayati.

[7] Sunarti. 2009. Minimasi Biaya Bahan Baku Melalui Pendekatan Perencanaan Kebutuhan Bahan Pada Unit Produksi Roti Kampus Polinela. Bandar Lampung : Program Studi Teknik Industri Universitas Malahayati.

[8] Wignjosoebroto, Sritomo. 2003. Pengantar Teknik dan Manajemen Industri. Edisi Kedua. Surabaya : Guna Widya. 